\title{
Medication adherence and persistence in chronic obstructive pulmonary disease patients receiving triple therapy in a USA commercially insured population
}

This article was published in the following Dove Medical Press journal:

International Journal of COPD

\author{
Michael Bogart' \\ Richard H Stanford' \\ François Laliberté \\ Guillaume Germain ${ }^{2}$ \\ Jennifer W Wu ${ }^{2}$ \\ Mei Sheng Duh ${ }^{3}$ \\ 'GlaxoSmithKline plc, Research \\ Triangle Park, NC, USA; ${ }^{2}$ Groupe \\ d'Analyse, Ltée, Montréal, QC, \\ Canada; ${ }^{3}$ Analysis Group Inc., Boston, \\ MA, USA
}

\begin{abstract}
Introduction: This longitudinal, retrospective cohort study of patients with COPD describes baseline characteristics, adherence, and persistence following initiation of inhaled corticosteroids (ICS)/long-acting $\beta_{2}$-agonists (LABA)/long-acting muscarinic antagonists (LAMA) from multiple inhaler triple therapy (MITT).

Methods: Patients aged $\geq 40$ years receiving MITT between January 2012 and September 2015 were identified from the IQVIA ${ }^{\text {TM }}$ Real-world Data Adjudicated Claims-USA database. MITT was defined as subjects with $\geq 1$ overlapping days' supply of three COPD medications (ICS, LABA, and LAMA). Adherence (proportion of days covered, PDC) and discontinuation (defined as a gap of $1,30,60$, or 90 days of supply in any of the three components of the triple therapy) were calculated for each patient over 12 months of follow-up. In addition, analyses were stratified by number of inhalers.

Results: In total, 14,635 MITT users were identified (mean age, 62 years). Mean PDC for MITT at 12 months was $0.37 \%$. Mean PDC for the ICS/LABA and LAMA component at 12 months was $49 \%(0.49 \pm 0.31$; median, 0.47$)$ and $54 \%(0.54 \pm 0.33 ; 0.56)$, respectively. The proportion of adherent patients (PDC $\geq 0.8$ ) at 12 months was $14 \%$ for MITT. Allowing for a 30-day gap from last day of therapy, $86 \%$ of MITT users discontinued therapy during follow-up.

Conclusion: Patients with COPD had low adherence to and persistence with MITT in a realworld setting. Mean PDC for each single inhaler component was higher than the mean PDC observed with MITT. Reducing the number of inhalers may improve overall adherence to intended triple therapy.
\end{abstract}

Keywords: chronic obstructive pulmonary disease, COPD, medication adherence, inhaled corticosteroids, ICS, long-acting $\beta_{2}$-agonists, LABA, long-acting muscarinic antagonists, LAMA, multiple inhaler triple therapy

\section{Introduction}

COPD is a complex, heterogeneous condition characterized by restriction of the airways. It worsens progressively over time, requiring treatment escalation. ${ }^{1}$ In the USA, around 16 million people have COPD and it is the third leading cause of death. ${ }^{2}$ The GOLD guidelines recommend the use of triple therapy, combining inhaled corticosteroids (ICS), long-acting $\beta_{2}$-agonists (LABA), and long-acting muscarinic antagonists (LAMA), in patients with COPD who have severe symptoms and are at risk of exacerbations. ${ }^{1}$ Together, ICS, LABA, and LAMA therapies help to relieve
Correspondence: Michael Bogart GlaxoSmithKline plc, 5 Moore Drive, Research Triangle Park, NC 27703, USA $\mathrm{Tel}+\mathrm{I} 9194830231$

Email michael.r.bogart@gsk.com 
symptoms by improving lung function, reducing systemic inflammation, reducing frequency of exacerbations, and slowing the progression of respiratory symptoms. ${ }^{1}$

Triple therapy has positive effects on lung function and COPD symptoms compared with dual therapy. ${ }^{3-13}$ However, current triple therapy regimens may involve the use of multiple inhalers, which results in complex treatment regimens. ${ }^{14,15}$ Patients receiving triple therapy can use either two different inhalers in the form of ICS/LABA + LAMA or LAMA/LABA + ICS, or three different inhalers in the form of ICS + LAMA + LABA. The complexity of the treatment regimen and types of inhaler are two of the many factors that affect adherence to medications. ${ }^{16,17}$ The use of multiple inhalers has been shown to negatively influence adherence to medication for a patient. ${ }^{1,18}$

Adherence to and persistence with medication are distinct, interrelated concepts. Adherence is described by the International Society for Pharmacoeconomics and Outcomes Research (ISPOR) as "the extent to which a patient acts in accordance with the prescribed interval and dose of a dosing regimen," whereas persistence is "the duration of time from initiation to discontinuation of therapy". ${ }^{19}$ Persistence is therefore also an important indication of patients' long-term behavior impacting clinical outcome. Factors associated with poor persistence in patients may include lack of symptoms, confusion around medications, and difficulty in handling the inhaler device. ${ }^{20}$ Among other factors, level of patient knowledge/education, inhaler convenience and satisfaction, age, adverse effects and medication costs may influence nonadherence in patients with COPD. ${ }^{21}$

Real-world studies on treatment patterns, specifically on adherence to, and persistence with, treatment regimens that use multiple inhalers among patients with COPD are limited. The objective of this longitudinal, retrospective cohort study was to better understand the real-world use of multiple inhaler triple therapy (MITT) in patients diagnosed with COPD in the USA population. More specifically, the study aimed to describe baseline characteristics and evaluate adherence and persistence following the initiation of inhaled triple therapy.

\section{Methods}

\section{Study design}

This is a retrospective, observational cohort, descriptive study of patients with COPD using triple therapy utilizing the IQVIA $^{\text {TM }}$ Real-world Data (RWD) Adjudicated Claims-USA database. Triple therapy was defined as concomitant use of two different inhalers in the form of ICS/LABA + LAMA or LABA/LAMA + ICS or use of three different inhalers in the form of ICS + LAMA + LABA. The algorithm for triple therapy identification, based on previous studies, ${ }^{22-24}$ was defined as an overlap of $\geq 1$ day of supply (or $\geq 30$ consecutive days as a sensitivity analysis) of all three triple therapy components (ICS, LAMA, and LABA). The date of the first overlapping days of supply with all three COPD medications of the triple therapy, between January 1, 2012 and September 30, 2015, was defined as the index date. The patients' baseline demographics and clinical characteristics were assessed in the 12 months prior to the index date. Patients were observed from the index date for a minimum of 12 months until the earliest date of health plan disenrollment or end of data availability (September 30, 2016), whichever occurred first. Baseline characteristics and adherence measures were stratified further by the number of inhalers (ie, two vs three inhalers), which was based on the number of inhalers used at the index date.

\section{Data source}

The IQVIA ${ }^{\text {TM }}$ RWD Adjudicated Claims-USA database was used to identify patients with COPD receiving inhaled triple therapy between January 1, 2011 and September 30, 2016. The database comprises fully adjudicated medical and pharmacy claims since 2006 on $>150$ million enrollees across all 50 states in the USA. The average length of health plan enrollment was $\sim 39$ months. The IQVIATM RWD Adjudicated Claims-USA database is, in general, representative of the commercially insured population. The database includes historical information on patient demographics, as well as inpatient, outpatient, and pharmacy claims; the data are anonymized and comply with the Health Insurance Portability and Accountability Act (HIPAA).

\section{Study population}

The following inclusion and exclusion criteria were used to select the study population. First, patients were required to have a minimum of 12 months of continuous eligibility before and after the index date. Second, patients were required to have at least two COPD diagnoses in the outpatient setting, or at least one in the inpatient or emergency room setting in the year prior to index date (International Classification of Diseases, 9th Revision, Clinical Modification, ICD-9-CM diagnosis code: 491.x, 492.x, 496.x; International Classification of Diseases, 10th Revision, Clinical Modification, ICD-10-CM diagnosis code: J41.X-J44.x). Third, patients were 40 years or older at index date. Fourth, patients who had at least one diagnosis for asthma (ICD-9-CM: 493.x; ICD-10-CM: J45.x) at any time prior to the index date were excluded. 


\section{Demographic and clinical characteristics}

Baseline characteristics included demographic information, as well as clinical characteristics and medication history evaluated at the index date or during the 12-month baseline period. More specifically, the following characteristics were included: age, sex, geographic region, insurance type, year of index date, medication use (COPD, cardiovascular disease, and diabetes), exacerbation history, Charlson Comorbidity Index (Quan update; CCI) score, ${ }^{25}$ and list of Elixhauser comorbidities. ${ }^{25,26}$ For the identification of COPD exacerbations, patients were identified as having either a moderate or a severe exacerbation. Moderate exacerbation was defined as a patient having an outpatient or emergency department visit with a diagnosis of COPD (ICD-9-CM: 491.x, 492.x, 496; ICD-10-CM: J41.x-J44.x) as a primary or secondary diagnosis and at least one dispensing for systemic corticosteroids (SCS) (intramuscular, intravenous, or oral) or antibiotic within 7 days following the encounter. Severe exacerbation was defined as an inpatient hospital stay with a diagnosis of COPD, either as a primary or a secondary diagnosis.

\section{Primary outcomes}

Adherence to triple therapy was measured at 3,6,9, and 12 months using the proportion of days covered (PDC) method. Adherence measures were reported for the 1-day and 30-day overlap cohorts and stratified by the number of inhalers. Persistence or nonpersistence with triple therapy was measured at 3, 6, 9, and 12 months after the index date. Nonpersistence (ie, discontinuation) was defined as a treatment gap of at least 30 days in any of the three components of triple therapy. Various treatment gaps $(1,30,60$, and 90 days $)$ were used to evaluate how treatment discontinuation could be affected. The median time to triple therapy nonpersistence was also calculated (ie, the time-point when the proportion of patients who were persisting with triple therapy was 50\%).

\section{Statistical analysis}

Baseline characteristics evaluated during the 12-month period prior to the index date were reported for the 1-day and 30-day overlap cohorts and stratified by number of inhalers (two vs three inhalers). The number of inhalers was determined at the index date. Characteristics were described using mean, $\mathrm{SD}$, median for continuous variables, and the frequency and proportion for categorical variables. Based on the triple therapy algorithm, adherence measures or PDC was calculated as the total number of overlapping days on therapy for all three triple therapy components (ICS, LABA, and LAMA), starting from the index date.
Days on triple therapy were then divided by a fixed time interval (90 days and 180 days). Although no retrospective claims studies have assessed adherence to triple therapy in COPD, this topic has been investigated in the context of hypertension and rheumatoid arthritis where patients were considered adherent to triple therapy if a PDC threshold of 0.8 was achieved. ${ }^{17,22,23,27,28}$ Therefore, a PDC $\geq 0.8$ was used to define adherence to triple therapy among patients with COPD. As a sensitivity analysis, a PDC $\geq 0.5$ was also considered. More specifically, mean PDC and adherence rates, defined as proportions of patients with $\mathrm{PDC} \geq 0.8$ or 0.5 , were reported. For patients who refilled a medication before their previous fill ran out, the refill date was shifted to the end of the first prescription days of supply. For example, a patient who refilled an ICS prescription 5 days before the end of the first 30-day ICS prescription was considered as using ICS therapy for a full 60-day period. Persistence was assessed using the Kaplan-Meier survival analysis.

\section{Results}

\section{Demographics and clinical characteristics}

A total of 14,635 and 6,658 triple therapy users were identified in the $\geq 1$ day and $\geq 30$ overlapping day cohorts, respectively (based on days of supply of ICS, LABA, and LAMA; Figure 1). Patient demographics and baseline characteristics are shown in Table 1 . In the $\geq 1$-day overlap cohort, patients had a mean age of 62 years, $43 \%$ were female, and had a mean CCI score of 2.4. The most frequent comorbidities were hypertension (61\%), cardiac arrhythmias (21\%), and diabetes $(20 \%)$. More than half of patients $(58 \%)$ experienced COPD exacerbations during the 12-month baseline period (moderate: $49 \%$; severe: 24\%). The mean number of COPDrelated hospitalizations per patient in the $\geq 1$-day overlap cohort during the 12-month baseline period was $1.3 \pm 0.8$, lasting 7.4 \pm 10.9 days on average. Patients also visited the emergency room or an outpatient clinic $1.4 \pm 1.2$ and 5.5 \pm 7.9 times, respectively (Table 1). The most frequently used maintenance therapies included LAMA (47\%), ICS/LABA (43\%), and ICS ( $8 \%)$, whereas the other most frequently used therapies included antibiotics (70\%), short-acting $\beta_{2}$-agonist (61\%), and SCS (48\%). Patients in the two-inhaler subgroup tended to be younger than those in the three-inhaler subgroup (mean age: 62 vs 65 years, respectively). Moreover, patients in the two- vs three-inhaler subgroup had a lower overall rate of exacerbations in the baseline period ( $58 \%$ vs $65 \%$, respectively) and mean CCI score (2.4 vs 2.5). Similar demographic and clinical characteristics were observed for patients in the 30-day overlap cohort. 


\section{1-day overlap}

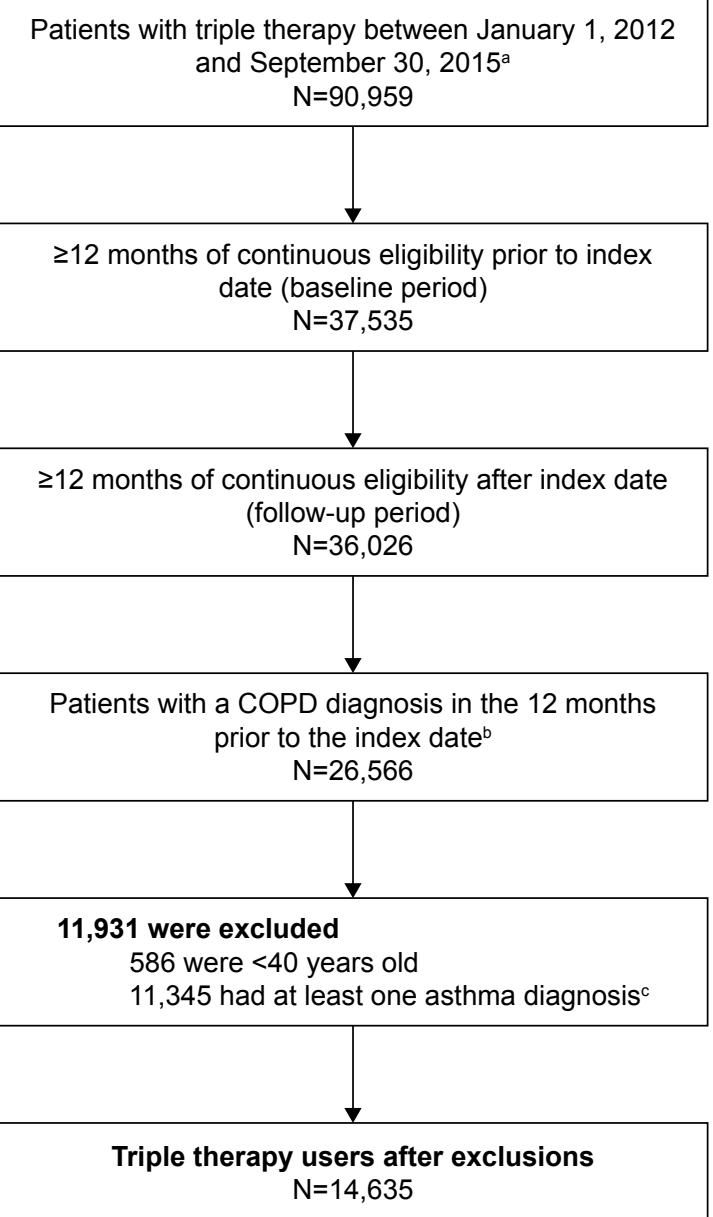

\section{0-day overlap}

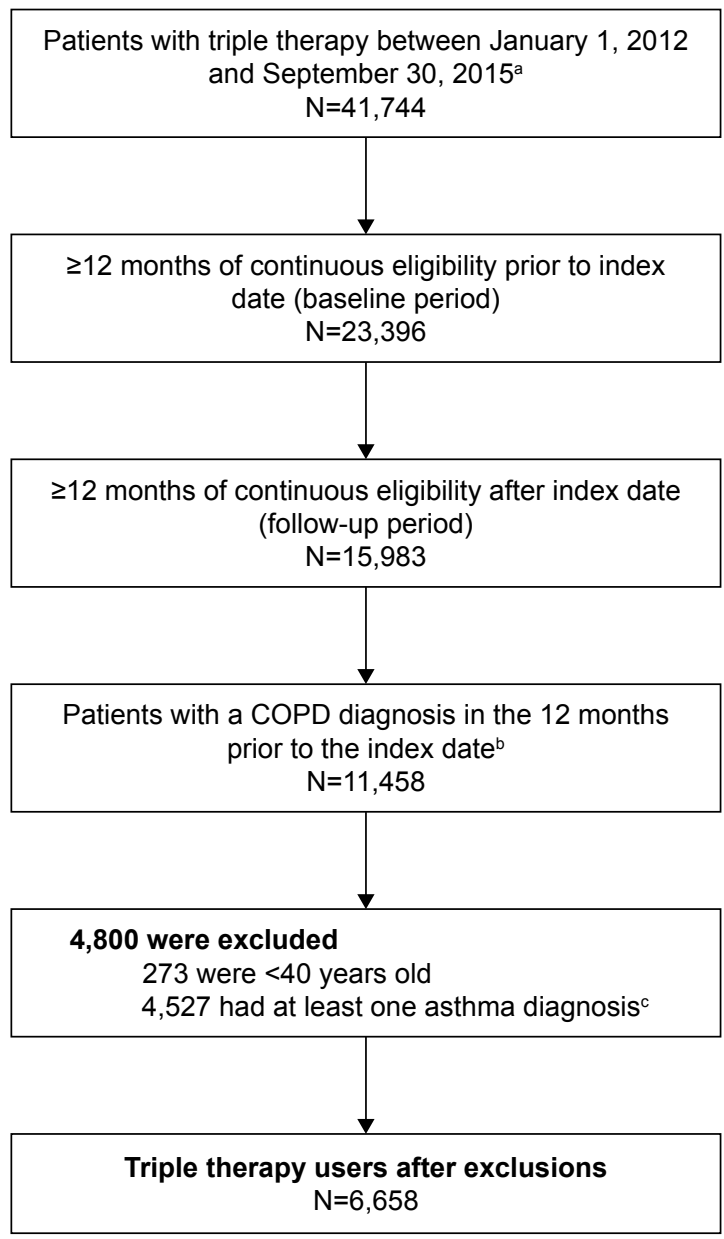

Figure I Flow chart of patients with COPD receiving triple therapy.

Notes: aTriple therapy was defined as an overlap of I- or 30-day supply of ICS, LABA, and LAMA. 'Patients with at least two COPD diagnoses in the outpatient setting or at least one in the inpatient or emergency room setting in the year prior to index date of triple therapy. 'Patients with at least one asthma diagnosis at any time prior to index date. Abbreviations: ICS, inhaled corticosteroids; LABA, long-acting $\beta_{2}$-agonists; LAMA, long-acting muscarinic antagonists.

\section{Adherence}

The PDC and proportion of patients who were adherent to triple therapy are presented in Table 2 . In the $\geq 1$-day overlap cohort, the mean PDC at 6 and 12 months for the overall population was 0.44 and 0.37 , respectively. More specifically, the mean PDC for the ICS/LABA and LAMA components at 12 months was 0.49 and 0.54 , respectively. The mean PDC for the overall population in the 30-day overlap cohort was 0.46 at 6 months and 0.37 at 12 months. Similarly, the mean PDC for the ICS/LABA and LAMA components at 12 months was 0.45 and 0.50 , respectively. The mean PDC for two inhalers compared with three inhalers was 0.37 and 0.32 , respectively, in the $\geq 1$-day overlap cohort. The proportion of triple therapy users in the 1-day overlap cohort who were adherent to therapy (PDC $\geq 0.8$ ) was $19 \%$ and $14 \%$ at 6 and 12 months, respectively. In general, greater adherence was found among patients who used two inhalers compared with those who used three inhalers (for the 1-day overlap cohort at 6 months: 19\% vs $12 \%$ and at 12 months: $14 \%$ vs $9 \%$ ). Adherence measures at 3 and 9 months are also reported for both $\geq 1$-day and 30-day overlap cohorts in the Appendix and support the observations for decreased adherence over time that are reported above: for example, in the 1-day overlap cohort at 3 months, $29 \%$ of triple therapy users were adherent (PDC $\geq 0.8$ ), decreasing to $15 \%$ of users at 9 months.

\section{Persistence}

Persistence with triple therapy using different gap definitions is shown in Figure 2A and B. The proportions of triple therapy users who discontinued at 3, 6, 9, and 12 months in the $\geq 1$-day overlap cohort with an allowable treatment gap 
Table I Demographic and clinical characteristics of triple therapy users

\begin{tabular}{|c|c|c|c|c|c|c|}
\hline \multirow[t]{3}{*}{ Characteristics } & \multicolumn{3}{|c|}{ Triple therapy users: $\geq \mathbf{I}$-day overlap ${ }^{a}$} & \multicolumn{3}{|c|}{ Triple therapy users: $30-$ day overlapa } \\
\hline & Overall & Two inhalers ${ }^{b}$ & Three inhalers $^{b}$ & Overall & Two inhalers ${ }^{b}$ & Three inhalers $^{\mathrm{b}}$ \\
\hline & $N=14,635$ & $N=14,403$ & $\mathrm{~N}=232$ & $\mathbf{N}=\mathbf{6 , 6 5 8}$ & $\mathbf{N}=6,6$ I I & $N=47$ \\
\hline Age (years), mean $\pm S D$ (median) & $61.9 \pm 8.5(61.0)$ & $61.8 \pm 8.5(61.0)$ & $64.5 \pm 8.6(63.0)$ & $61.8 \pm 8.6(61.0)$ & $61.8 \pm 8.6(61.0)$ & $65.3 \pm 8.4(63.0)$ \\
\hline Gender, female, n (\%) & $6,326(43.2)$ & $6,230(43.3)$ & $96(41.4)$ & $2,853(42.9)$ & $2,833(42.9)$ & $20(42.6)$ \\
\hline \multicolumn{7}{|l|}{ Region, ${ }^{\mathrm{C}} \mathrm{n}(\%)$} \\
\hline Midwest & $4,113(28.1)$ & $4,030(28.0)$ & $83(35.8)$ & $\mathrm{I}, 895(28.5)$ & $\mathrm{I}, 880(28.4)$ & $15(31.9)$ \\
\hline South & $5,404(36.9)$ & $5,337(37.1)$ & $67(28.9)$ & $2,543(38.2)$ & $2,528(38.2)$ & $15(31.9)$ \\
\hline West & I,235 (8.4) & $\mathrm{I}, 202(8.3)$ & $33(14.2)$ & $515(7.7)$ & $508(7.7)$ & $7(14.9)$ \\
\hline Northeast & $3,594(24.6)$ & $3,547(24.6)$ & $47(20.3)$ & I,584 (23.8) & $1,574(23.8)$ & $10(21.3)$ \\
\hline Unknown & $289(2.0)$ & $287(2.0)$ & $2(0.9)$ & $121(1.8)$ & $121(1.8)$ & $0(0.0)$ \\
\hline \multicolumn{7}{|l|}{ Insurance product type, ${ }^{\mathrm{c}} \mathrm{n}(\%)$} \\
\hline PPO & $10,918(74.6)$ & $10,765(74.7)$ & $153(65.9)$ & $5,130(77.1)$ & $5,096(77.1)$ & $34(72.3)$ \\
\hline $\mathrm{HMO}$ & $2,336(16.0)$ & $2,286(15.9)$ & $50(21.6)$ & $896(13.5)$ & $888(13.4)$ & $8(17.0)$ \\
\hline Indemnity/traditional & $618(4.2)$ & $599(4.2)$ & $19(8.2)$ & $289(4.3)$ & $286(4.3)$ & $3(6.4)$ \\
\hline POS & $547(3.7)$ & $538(3.7)$ & $9(3.9)$ & $231(3.5)$ & $229(3.5)$ & $2(4.3)$ \\
\hline CDHP & $80(0.5)$ & $79(0.5)$ & $\mathrm{I}(0.4)$ & $36(0.5)$ & $36(0.5)$ & $0(0.0)$ \\
\hline HSA & $5(0.0)$ & $5(0.0)$ & $0(0.0)$ & I $(0.0)$ & $\mathrm{I}(0.0)$ & $0(0.0)$ \\
\hline Unknown & $131(0.9)$ & $13 \mid(0.9)$ & $0(0.0)$ & $75(I . I)$ & $75(1.1)$ & $0(0.0)$ \\
\hline \multicolumn{7}{|l|}{ Year of index date, $\mathrm{n}(\%)$} \\
\hline 2012 & $4,678(32.0)$ & $4,604(32.0)$ & $74(31.9)$ & $2,237(33.6)$ & $2,220(33.6)$ & $17(36.2)$ \\
\hline 2013 & $3,924(26.8)$ & $3,862(26.8)$ & $62(26.7)$ & I,826 (27.4) & $1,815(27.5)$ & II (23.4) \\
\hline 2014 & $3,406(23.3)$ & $3,355(23.3)$ & $51(22.0)$ & $\mathrm{I}, 495(22.5)$ & $\mathrm{I}, 485(22.5)$ & $10(21.3)$ \\
\hline 2015 & $2,627(I 8.0)$ & $2,582(17.9)$ & $45(19.4)$ & $1,100(16.5)$ & $1,091(16.5)$ & $9(19.1)$ \\
\hline \multicolumn{7}{|l|}{ Exacerbations, ${ }^{\mathrm{d}} \mathrm{n}(\%)$} \\
\hline Any & $8,447(57.7)$ & $8,296(57.6)$ & $151(65.1)$ & $3,529(53.0)$ & $3,503(53.0)$ & $26(55.3)$ \\
\hline Moderate & $7,102(48.5)$ & $6,967(48.4)$ & $135(58.2)$ & $2,830(42.5)$ & $2,810(42.5)$ & $20(42.6)$ \\
\hline Severe & $3,562(24.3)$ & $3,483(24.2)$ & $79(34.1)$ & $1,600(24.0)$ & $1,584(24.0)$ & $16(34.0)$ \\
\hline \multicolumn{7}{|l|}{ COPD-related medication use, ${ }^{\mathrm{d}} \mathrm{n}(\%)$} \\
\hline \multicolumn{7}{|l|}{ Maintenance therapies } \\
\hline Any & II,440 (78.2) & $11,220(77.9)$ & $220(94.8)$ & $3,549(53.3)$ & $3,513(53.1)$ & $36(76.6)$ \\
\hline LAMA & $6,819(46.6)$ & $6,646(46.1)$ & $173(74.6)$ & $1,903(28.6)$ & $\mathrm{I}, 878(28.4)$ & $25(53.2)$ \\
\hline ICS/LABA & $6,317(43.2)$ & 6,299 (43.7) & $18(7.8)$ & I,924 (28.9) & I,92I (29.1) & $3(6.4)$ \\
\hline ICS & $\mathrm{I}, 166(8.0)$ & $\mathrm{I}, 026(7.1)$ & $140(60.3)$ & $430(6.5)$ & $409(6.2)$ & $21(44.7)$ \\
\hline LABA & $334(2.3)$ & $206(1.4)$ & $128(55.2)$ & $99(1.5)$ & $80(1.2)$ & $19(40.4)$ \\
\hline LABA/LAMA & $55(0.4)$ & $55(0.4)$ & $0(0.0)$ & $18(0.3)$ & $18(0.3)$ & $0(0.0)$ \\
\hline \multicolumn{7}{|l|}{ Other therapies } \\
\hline Antibiotics & $10,287(70.3)$ & $10,120(70.3)$ & $167(72.0)$ & $4,548(68.3)$ & $4,518(68.3)$ & $30(63.8)$ \\
\hline SABA & $8,880(60.7)$ & $8,710(60.5)$ & $170(73.3)$ & $3,387(50.9)$ & $3,362(50.9)$ & $25(53.2)$ \\
\hline SCS & $7,056(48.2)$ & $6,924(48.1)$ & $132(56.9)$ & $2,942(44.2)$ & $2,917(44.1)$ & $25(53.2)$ \\
\hline SABA/SAMA & $2,879(19.7)$ & $2,806(19.5)$ & $73(31.5)$ & $\mathrm{I}, 142(17.2)$ & $1,136(17.2)$ & $6(12.8)$ \\
\hline SAMA & $538(3.7)$ & $514(3.6)$ & $24(10.3)$ & $206(3.1)$ & $203(3.1)$ & $3(6.4)$ \\
\hline Phosphodiesterase-4 inhibitor & $219(1.5)$ & $205(1.4)$ & $14(6.0)$ & $76(1.1)$ & $74(1.1)$ & $2(4.3)$ \\
\hline Methylxanthines & $192(1.3)$ & $186(1.3)$ & $6(2.6)$ & $68(1.0)$ & $68(1.0)$ & $0(0.0)$ \\
\hline $\begin{array}{l}\mathrm{CCl} \text { score, }{ }^{\mathrm{d}} \\
\text { mean } \pm \mathrm{SD} \text { (median) }\end{array}$ & $\begin{array}{l}2.36 \pm 2.03 \\
(2.00)\end{array}$ & $\begin{array}{l}2.36 \pm 2.03 \\
(2.00)\end{array}$ & $\begin{array}{l}2.54 \pm 2.13 \\
(2.00)\end{array}$ & $\begin{array}{l}2.35 \pm 2.07 \\
(2.00)\end{array}$ & $\begin{array}{l}2.35 \pm 2.07 \\
(2.00)\end{array}$ & $\begin{array}{l}2.47 \pm 1.91 \\
(2.00)\end{array}$ \\
\hline
\end{tabular}


Table I (Continued)

\begin{tabular}{|c|c|c|c|c|c|c|}
\hline \multirow[t]{3}{*}{ Characteristics } & \multicolumn{3}{|c|}{ Triple therapy users: $\geq \mathbf{I}$-day overlap ${ }^{a}$} & \multicolumn{3}{|c|}{ Triple therapy users: 30 -day overlap ${ }^{a}$} \\
\hline & Overall & Two inhalers $^{b}$ & Three inhalers $^{\mathrm{b}}$ & Overall & Two inhalers $^{b}$ & Three inhalers $^{\mathrm{b}}$ \\
\hline & $N=14,635$ & $N=14,403$ & $\mathbf{N}=\mathbf{2 3 2}$ & $\mathbf{N}=6,658$ & $\mathbf{N}=6,6 \mathrm{II}$ & $\mathbf{N}=47$ \\
\hline \multicolumn{7}{|c|}{ Key comorbidities from the $\mathrm{CCl}$ score, ${ }^{\mathrm{d}} \mathrm{n}(\%)$} \\
\hline Diabetes, uncomplicated & $2,855(19.5)$ & $2,806(19.5)$ & $49(21.1)$ & I,347 (20.2) & $1,336(20.2)$ & II (23.4) \\
\hline Peripheral vascular disorders & $2,138(14.6)$ & $2,101(14.6)$ & $37(15.9)$ & $1,000(15.0)$ & $995(15.1)$ & $5(10.6)$ \\
\hline Congestive heart failure & $2,125(14.5)$ & $2,076(14.4)$ & $49(21.1)$ & $992(14.9)$ & $978(14.8)$ & $14(29.8)$ \\
\hline \multicolumn{7}{|c|}{ Key comorbidities from the Elixhauser comorbidity index score, ${ }^{d} \mathrm{n}(\%)$} \\
\hline Hypertension, uncomplicated & $8,870(60.6)$ & $8,728(60.6)$ & $142(6 \mid .2)$ & $4,039(60.7)$ & $4,007(60.6)$ & $32(68.1)$ \\
\hline Cardiac arrhythmias & $3,019(20.6)$ & $2,955(20.5)$ & $64(27.6)$ & I,378 (20.7) & 1,362 (20.6) & $16(34.0)$ \\
\hline Depression & $2,586(17.7)$ & $2,543(17.7)$ & $43(18.5)$ & I, I $24(16.9)$ & I, II7 (16.9) & $7(14.9)$ \\
\hline Fluid and electrolyte disorders & $2,162(14.8)$ & $2,121(14.7)$ & $4 I(17.7)$ & $984(14.8)$ & $976(14.8)$ & $8(17.0)$ \\
\hline Hypothyroidism & $\mathrm{I}, 860(12.7)$ & $1,82 I(12.6)$ & $39(16.8)$ & $830(12.5)$ & $824(12.5)$ & $6(12.8)$ \\
\hline \multicolumn{7}{|c|}{ COPD-related healthcare utilization, ${ }^{d}$ mean \pm SD } \\
\hline Hospitalization, n & $1.3 \pm 0.8$ & $1.3 \pm 0.7$ & $1.5 \pm 1.0$ & $1.3 \pm 0.7$ & $1.3 \pm 0.7$ & $1.4 \pm 0.8$ \\
\hline Length of stay, days & $7.4 \pm 10.9$ & $7.4 \pm 10.8$ & $8.3 \pm 14.5$ & $7.5 \pm 9.4$ & $7.4 \pm 9.0$ & $12.3 \pm 27.9$ \\
\hline ER visits, $n$ & $1.4 \pm 1.2$ & $1.4 \pm 1.2$ & $1.4 \pm 0.8$ & $1.4 \pm 0.9$ & $1.4 \pm 0.9$ & $1.5 \pm 0.8$ \\
\hline Outpatient visits, $\mathrm{n}$ & $5.5 \pm 7.9$ & $5.5 \pm 7.9$ & $9.5 \pm 9.5$ & $5.1 \pm 7.7$ & $5.1 \pm 7.7$ & $7.6 \pm 7.5$ \\
\hline
\end{tabular}

Notes: ${ }^{\text {TT}}$ Triple therapy was defined as an overlap of I- or 30-day supply of ICS, LABA, and LAMA. ${ }^{\circ}$ Two inhalers included ICS/LABA + LAMA and ICS + LABA/LAMA and three inhalers included ICS + LABA + LAMA. The number of inhalers was determined at the index date. 'Evaluated at the index date. ${ }^{\mathrm{d} E v a l u a t e d}$ during a I2-month baseline period. Abbreviations: $\mathrm{CCl}$, Charlson Comorbidity Index (Quan update); CDHP, consumer directed health care; ER, emergency room; HMO, health maintenance organization; HSA, health savings account; ICS, inhaled corticosteroid; LABA, long-acting $\beta_{2}$-agonists; LAMA, long-acting muscarinic antagonists; POS, point of service; PPO, preferred provider organization; SABA, short-acting $\beta_{2}$-agonists; SAMA, short-acting muscarinic antagonists; SCS, systemic corticosteroids.

of 30 -days were $62 \%, 78 \%, 83 \%$, and $87 \%$, respectively. Similar discontinuation rates were observed when the allowable treatment gaps were varied. With an allowable treatment gap of no more than 60 days, $51 \%, 67 \%, 74 \%$, and $78 \%$ of patients discontinued at 3,6, 9, and 12 months, respectively. For the same respective time-points with a treatment gap of no more than 90 days, $45 \%, 60 \%, 68 \%$, and $72 \%$ of patients discontinued.

Table 2 Adherence to triple therapy ${ }^{a}$

\begin{tabular}{|c|c|c|c|c|c|c|}
\hline \multirow{3}{*}{$\begin{array}{l}\text { PDC of overlapping } \\
\text { ICS, LABA, and } \\
\text { LAMA }\end{array}$} & \multicolumn{3}{|c|}{ Triple therapy users: $\geq \mathbf{I}$-day overlap ${ }^{b}$} & \multicolumn{3}{|c|}{ Triple therapy users: 30 -day overlap } \\
\hline & Overall & Two inhalers ${ }^{c}$ & Three inhalers $^{c}$ & Overall & Two inhalers ${ }^{c}$ & Three inhalers $^{c}$ \\
\hline & $N=14,635$ & $N=14,403$ & $\mathbf{N}=\mathbf{2 3 2}$ & $N=6,658$ & $N=6,611$ & $\mathbf{N}=47$ \\
\hline \multicolumn{7}{|c|}{ PDC at 6 months, mean \pm SD (median) } \\
\hline Triple therapy & $0.44 \pm 0.30(0.37)$ & $0.44 \pm 0.30(0.37)$ & $0.38 \pm 0.27(0.32)$ & $0.46 \pm 0.29(0.39)$ & $0.46 \pm 0.29(0.39)$ & $0.45 \pm 0.25(0.4 I)$ \\
\hline LAMA only & $0.61 \pm 0.32(0.67)$ & $0.61 \pm 0.32(0.67)$ & $0.70 \pm 0.30(0.79)$ & $0.59 \pm 0.3 \mathrm{I}(0.57)$ & $0.59 \pm 0.3 \mathrm{I}(0.56)$ & $0.69 \pm 0.28(0.78)$ \\
\hline ICS/LABA only & $0.55 \pm 0.30(0.5 \mathrm{I})$ & $0.56 \pm 0.30(0.5 \mathrm{I})$ & $0.45 \pm 0.25(0.50)$ & $0.54 \pm 0.30(0.50)$ & $0.54 \pm 0.30(0.50)$ & $0.5 \mathrm{I} \pm 0.30(0.50)$ \\
\hline \multicolumn{7}{|c|}{ Adherent to triple therapy, $\mathrm{n}(\%)$} \\
\hline $\mathrm{PDC} \geq 0.5$ & $5,720(39.1)$ & $5,650(39.2)$ & $70(30.2)$ & $2,729(4 I .0)$ & $2,7 \mid 4(4 \mid . I)$ & $15(31.9)$ \\
\hline $\mathrm{PDC} \geq 0.8$ & $2,768(18.9)$ & $2,74 \mid(19.0)$ & $27(11.6)$ & $1,319(19.8)$ & $1,313(19.9)$ & $6(12.8)$ \\
\hline \multicolumn{7}{|c|}{ PDC at 12 months, mean \pm SD (median) } \\
\hline Triple therapy & $0.37 \pm 0.30(0.26)$ & $0.37 \pm 0.30(0.26)$ & $0.32 \pm 0.28(0.22)$ & $0.37 \pm 0.29(0.25)$ & $0.37 \pm 0.29(0.25)$ & $0.36 \pm 0.27(0.24)$ \\
\hline LAMA only & $0.54 \pm 0.33(0.56)$ & $0.54 \pm 0.33(0.55)$ & $0.63 \pm 0.32(0.67)$ & $0.50 \pm 0.33(0.49)$ & $0.50 \pm 0.33(0.49)$ & $0.59 \pm 0.33(0.58)$ \\
\hline ICS/LABA only & $0.49 \pm 0.31(0.47)$ & $0.49 \pm 0.32(0.47)$ & $0.4 \mathrm{I} \pm 0.27(0.36)$ & $0.45 \pm 0.31(0.42)$ & $0.45 \pm 0.3 \mathrm{I}(0.42)$ & $0.55 \pm 0.25(0.56)$ \\
\hline \multicolumn{7}{|c|}{ Adherent to triple therapy, $\mathrm{n}(\%)$} \\
\hline$P D C \geq 0.5$ & $4,573(31.2)$ & $4,5 I 7(3 I .4)$ & $56(24.1)$ & $\mathrm{I}, 987(29.8)$ & $1,972(29.8)$ & $15(31.9)$ \\
\hline$P D C \geq 0.8$ & $2,020(13.8)$ & $2,000(\mid 3.9)$ & $20(8.6)$ & $908(13.6)$ & $904(13.7)$ & $4(8.5)$ \\
\hline
\end{tabular}

Notes: 'Defined as the sum of the number of overlapping days' supply of ICS, LABA, and LAMA divided by a fixed time interval starting from the index date. ${ }^{\circ}$ Triple therapy was defined as an overlap of I- or 30-day supply of ICS, LABA, and LAMA. 'Two inhalers included ICS/LABA + LAMA and ICS + LABA/LAMA and three inhalers included ICS + LABA + LAMA. The number of inhalers was determined at the index date.

Abbreviations: ICS, inhaled corticosteroids; LABA, long-acting $\beta_{2}$-agonists; LAMA, long-acting muscarinic-antagonists; PDC, proportion of days covered. 

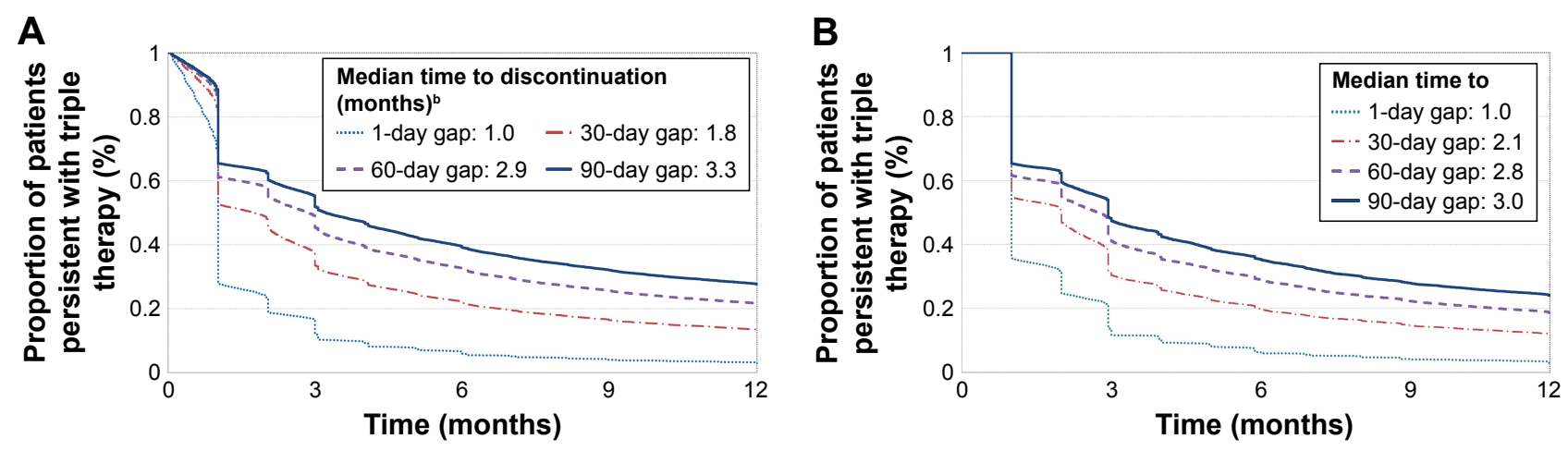

Figure 2 (A) Kaplan-Meier rates of persistence with triple therapy: $\geq 1$-day overlap cohort $(N=14,635)$. ${ }^{\text {(B) }}$ (B) Kaplan-Meier rates of persistence with triple therapy: 30 -day overlap cohort $(\mathrm{N}=6,658)$.

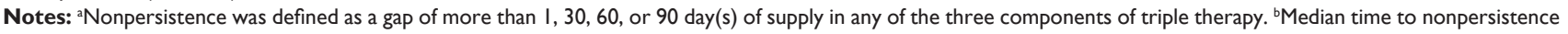
was defined as the time point when proportion of patients persistent with triple therapy dropped to $50 \%$.

\section{Discussion}

This study on adherence to, and persistence with, MITT in a real-world setting showed that patients with COPD had low adherence and persistence over a 12-month period. The mean PDC for a single inhaler (ICS/LABA or LAMA) was higher than for multiple inhaler triple therapy. The results of this study highlight suboptimal adherence to and persistence with inhaled triple therapy. However, as patients demonstrated higher adherence when treated with two inhalers vs three inhalers, this suggests that simplifying the treatment regimens may increase adherence and persistence for patients with COPD. Although health outcomes were not recorded during this study, nonadherence has been suggested to impact the effectiveness of triple therapy ${ }^{29}$ and therefore improving adherence and persistence through simplification of therapy may improve health outcomes for patients with COPD.

The GOLD guidelines have suggested the use of triple therapy was effective at reducing exacerbations. ${ }^{1}$ Indeed, many systematic reviews on randomized controlled trials comparing triple therapy with either LAMA monotherapy, LAMA/LABA dual therapy, or ICS/LABA dual therapy have demonstrated decreased exacerbations and hospitalizations and improved COPD-related health outcomes with MITT. ${ }^{30,31}$ Despite the benefits of the MITT in the clinical setting of randomized controlled trials, there is limited research on adherence to and persistence with MITT for patients with COPD in the real-world setting. In previous studies characterizing patients with COPD using MITT, it was found that patients were generally older than 60 years, were predominately male, had concurrent congestive heart failure and diabetes, and were frequent users of antibiotics, ${ }^{32-34}$ all of which were consistent with our results.

Nonadherence to COPD-related medications and factors associated with nonadherence in patients with COPD has also been explored in several previous studies. Nonadherence to treatment may negatively influence the effectiveness of the triple therapy regimen and may result in the worsening of clinical symptoms or other poor health outcomes. ${ }^{29}$ Problems with medication adherence among patients with COPD have been well documented worldwide. ${ }^{35-39}$ Dhamane et al, using a large administrative claims database ( $\mathrm{N}=14,117$; mean age, 69.9 years), observed that $79.2 \%$ of patients were nonadherent to maintenance COPD medications with a mean PDC of $0.47 .^{40}$ In another recent large retrospective cohort study based on claims data provided by a German statutory health insurance fund $(\mathrm{N}=45,937)$, and Mueller et al, it was reported that approximately two-thirds of patients with COPD failed to continue treatment after 12 months. ${ }^{41}$ Nonadherence is associated with reductions in health-related quality of life (HRQOL) $)^{21}$ and according to a systematic literature review, the relationship between medication adherence and HRQOL may be bidirectional. ${ }^{42}$ The effect of medication adherence on HRQOL might be influenced by the effectiveness of therapy and the potential negative effects of therapy (ie, side effects, daily life limitation of therapy, social stigma). In turn, an increased HRQOL might trigger nonadherence (ie, patients feel better and so they stop taking their maintenance medication). ${ }^{42}$ Improved adherence to maintenance therapies in COPD is needed to help reduce the clinical and economic burdens of the disease. ${ }^{43,44}$

Nonadherence to treatment may also be, in part, a reflection of regimen complexity. Use of a single inhaler has been associated with improved adherence and persistence compared with using more than one inhaler ${ }^{16}$ However, when examining the impact of the number of doses per inhaler, in a retrospective observational study of LABAs in which a cohort of 475 patients with COPD used a multiple-dose 
inhaler, and a cohort of 100 patients used a single-dose inhaler, no difference in patient persistence was observed between the patient groups. ${ }^{45}$ Further research is therefore needed to compare adherence and persistence in patients with COPD who are using one vs more than one inhaler, and patients using a multiple-dose vs a single-dose inhaler.

This retrospective cohort study using the IQVIA ${ }^{\mathrm{TM}}$ RWD Adjudicated Claims-USA database offers several advantages. First, the use of this database allowed the evaluation of characteristics, treatment patterns, adherence, and persistence of a large cohort of COPD patients using MITT in a real-world setting. Second, given the complexity and lack of consensus of the best adherence measures in the context of multiple therapies, this study was able to explore and utilize several adherence definitions as suggested by the literature.

Despite the strengths of this study, there were limitations that should be considered. First, COPD medications can also be used to treat patients with asthma. Although we excluded patients with at least one diagnosis of asthma prior to index date, we cannot ensure that ICS, LABA, and/or LAMA were used for the treatment of COPD specifically. Second, depending on the adherence measures chosen, we could have underestimated or overestimated adherence. ${ }^{46}$ However, there is currently no consensus on the types of adherence measures for the use of concurrent or multiple medications. In this study, we calculated adherence measures as the total number of overlapping days on therapy for all three triple therapy components (ICS, LABA, and LAMA). Third, spirometry results were not available in the current claims database. Therefore, a COPD diagnosis could not be confirmed. Finally, administrative claims databases or pharmacy dispensing records have several advantages over other methods of assessing adherence, including ease of data collection through closed pharmacy systems, the avoidance of tampering and recall bias, and the capacity for population level analyses, ${ }^{47}$ but a dispensed medication does not necessarily indicate the patient actually used the medication as prescribed. Consequently, adherence could be overestimated.

\section{Conclusion}

This study in a real-world setting showed that patients with COPD had low adherence and persistence to multiple inhaler triple therapy over a 12-month period, but that adherence was higher with regimens requiring two inhalers vs three. This indicates that simplifying triple inhaler treatment regimens may increase adherence and persistence for patients with COPD, and, by avoiding treatment discontinuation, may result in associated improvements in health outcomes.

\section{Originality and clinical relevance statement}

This longitudinal, retrospective cohort study on adherence to, and persistence with, triple therapy in a real-world setting showed that patients with COPD had low adherence and persistence over a 12 -month period. Simplifying the triple therapy regimen by reducing the number of inhalers may therefore be beneficial.

\section{Data sharing statement}

GlaxoSmithKline plc makes available anonymized individual participant data and associated documents from interventional clinical studies which evaluate medicines, upon approval of proposals submitted to www.clinicalstudydatarequest.com. To access data for other types of GlaxoSmithKline plc sponsored research, for study documents without patientlevel data and for clinical studies not listed, please submit an enquiry via the website. The data that support the findings of this study are available from IQVIA but restrictions apply to the availability of these data, which were used under license for the current study, and so are not publicly available.

\section{Acknowledgments}

A description of the study and some of the results described in this article have been reported previously in the form of an abstract for the American Thoracic Society 2018 International Conference. ${ }^{48}$ This study was funded by GlaxoSmithKline plc. (Study HO-17-17694). Medical writing support in the form of development of the draft outline and manuscript first draft in consultation with the authors, editorial suggestions to draft versions of this paper, assembling tables and figures, collating author comments, copyediting, referencing, and graphic services was provided by Catherine Amey, BSc of Gardiner-Caldwell Communications, Macclesfield, UK and was funded by GlaxoSmithKline plc.

\section{Author contributions}

All authors contributed to data analysis, drafting and revising the article, gave final approval of the version to be published, and agree to be accountable for all aspects of the work.

\section{Disclosure}

MB and RHS are employees of GlaxoSmithKline plc. and own shares in GSK. FL, GG, JWW, and MSD are employees of Analysis Group, Inc., a consulting company that has received research funds from GlaxoSmithKline plc. to conduct this study but they were not paid for manuscript 
development. The authors report no other conflicts of interest in this work.

\section{References}

1. GOLD [homepage on the Internet]. Global strategy for the diagnosis, management and prevention of COPD, 2018. Available from: http:// goldcopd.org. Accessed May 23, 2018.

2. CDC [homepage on the Internet]. Chronic Obstructive Pulmonary Disease (COPD). National Center for Chronic Disease Prevention and Health Promotion, Division of Population Health [updated June 6, 2018] Available from: www.cdc.gov/copd/index.html. Accessed July 2, 2018

3. Cazzola M, Andò F, Santus P, et al. A pilot study to assess the effects of combining fluticasone propionate/salmeterol and tiotropium on the airflow obstruction of patients with severe-to-very severe COPD. Pulm Pharmacol Ther. 2007;20(5):556-561.

4. Hanania NA, Crater GD, Morris AN, Emmett AH, O'Dell DM, Niewoehner DE. Benefits of adding fluticasone propionate/salmeterol to tiotropium in moderate to severe COPD. Respir Med. 2012;106(1):91-101.

5. Jung KS, Park HY, Park SY, et al. Comparison of tiotropium plus fluticasone propionate/salmeterol with tiotropium in COPD: a randomized controlled study. Respir Med. 2012;106(3):382-389.

6. Welte T, Miravitlles M, Hernandez P, et al. Efficacy and tolerability of budesonide/formoterol added to tiotropium in patients with chronic obstructive pulmonary disease. Am J Respir Crit Care Med. 2009;180(8):741-750.

7. Chatterjee A, Shah M, D'Souza AO, Bechtel B, Crater G, Dalal AA. Observational study on the impact of initiating tiotropium alone versus tiotropium with fluticasone propionate/salmeterol combination therapy on outcomes and costs in chronic obstructive pulmonary disease. Respir Res. 2012;13(1):15.

8. Short PM, Williamson PA, Elder DHJ, Lipworth SIW, Schembri S, Lipworth BJ. The impact of tiotropium on mortality and exacerbations when added to inhaled corticosteroids and long-acting $\beta$-agonist therapy in COPD. Chest. 2012;141(1):81-86.

9. Wedzicha JA, Decramer M, Ficker JH, et al. Analysis of chronic obstructive pulmonary disease exacerbations with the dual bronchodilator QVA149 compared with glycopyrronium and tiotropium (SPARK): a randomised, double-blind, parallel-group study. Lancet Respir Med 2013;1(3):199-209.

10. Singh D, Papi A, Corradi M, et al. Single inhaler triple therapy versus inhaled corticosteroid plus long-acting $\beta 2$-agonist therapy for chronic obstructive pulmonary disease (TRILOGY): a double-blind, parallel group, randomised controlled trial. Lancet. 2016;388(10048): 963-973.

11. Siler TM, Kerwin E, Sousa AR, Donald A, Ali R, Church A. Efficacy and safety of umeclidinium added to fluticasone furoate/vilanterol in chronic obstructive pulmonary disease: results of two randomized studies. Respir Med. 2015;109(9):1155-1163.

12. Vestbo J, Papi A, Corradi M, et al. Single inhaler extrafine triple therapy versus long-acting muscarinic antagonist therapy for chronic obstructive pulmonary disease (TRINITY): a double-blind, parallel group, randomised controlled trial. Lancet. 2017;389(10082): 1919-1929.

13. Lipson DA, Barnacle H, Birk R, et al. FULFIL trial: Once-daily triple therapy for patients with chronic obstructive pulmonary disease. Am J Respir Crit Care Med. 2017;196(4):438-446.

14. Bosnic-Anticevich S, Chrystyn H, Costello RW, et al. The use of multiple respiratory inhalers requiring different inhalation techniques has an adverse effect on COPD outcomes. Int J Chron Obstruct Pulmon Dis. 2017;12:59-71.

15. Molimard M, Colthorpe P. Inhaler devices for chronic obstructive pulmonary disease: insights from patients and healthcare practitioners. J Aerosol Med Pulm Drug Deliv. 2015;28(3):219-228.

16. Rau JL. Determinants of patient adherence to an aerosol regimen. Respir Care. 2005;50(10):1346-1356.
17. Krueger KP, Berger BA, Felkey B. Medication adherence and persistence: a comprehensive review. Adv Ther. 2005;22(4):313-356.

18. Toy EL, Beaulieu NU, Mchale JM, et al. Treatment of COPD: relationships between daily dosing frequency, adherence, resource use, and costs. Respir Med. 2011;105(3):435-441.

19. Cramer JA, Roy A, Burrell A, et al. Medication compliance and persistence: terminology and definitions. Value Health. 2008;11(1): 44-47.

20. Bender BG, Hernandez Vecino RA, Mcgrath K, Jones S. Comparative analysis of persistence to treatment among patients with asthma or COPD receiving AirFluSal forspiro or seretide diskus salmeterol/ fluticasone propionate combination therapy. J Allergy Clin Immunol Pract. 2016;4(5):884-889.

21. Mäkelä MJ, Backer V, Hedegaard M, Larsson K. Adherence to inhaled therapies, health outcomes and costs in patients with asthma and COPD. Respir Med. 2013;107(10):1481-1490.

22. Xie L, Frech-Tamas F, Marrett E, Baser O. A medication adherence and persistence comparison of hypertensive patients treated with single-, double- and triple-pill combination therapy. Curr Med Res Opin. 2014; 30(12):2415-2422.

23. Panjabi S, Lacey M, Bancroft T, Cao F. Treatment adherence, clinical outcomes, and economics of triple-drug therapy in hypertensive patients. J Am Soc Hypertens. 2013;7(1):46-60.

24. Bonafede M, Johnson BH, Tang DH, Shah N, Harrison DJ, Collier DH. Etanercept-methotrexate combination therapy initiators have greater adherence and persistence than triple therapy initiators with rheumatoid arthritis. Arthritis Care Res. 2015;67(12):1656-1663.

25. Quan $\mathrm{H}$, Sundararajan V, Halfon $\mathrm{P}$, et al. Coding algorithms for defining comorbidities in ICD-9-CM and ICD-10 administrative data. Med Care. 2005;43(11):1130-1139.

26. Elixhauser A, Steiner C, Harris DR, Coffey RM. Comorbidity measures for use with administrative data. Med Care. 1998;36(1):8-27.

27. Dolce JJ, Crisp C, Manzella B, Richards JM, Hardin JM, Bailey WC. Medication adherence patterns in chronic obstructive pulmonary disease. Chest. 1991;99(4):837-841.

28. Restrepo RD, Alvarez MT, Wittnebel LD, et al. Medication adherence issues in patients treated for COPD. Int J Chron Obstruct Pulmon Dis. 2008;3(3):371-384.

29. Martin LR, Williams SL, Haskard KB, Dimatteo MR. The challenge of patient adherence. Ther Clin Risk Manag. 2005;1(3): 189-199.

30. Karner C, Cates CJ. Long-acting beta 2 -agonist in addition to tiotropium versus either tiotropium or long-acting beta ${ }_{2}$-agonist alone for chronic obstructive pulmonary disease. Cochrane Database Syst Rev. 2011;10: CD008532.

31. Montuschi P, Malerba M, Macis G, Mores N, Santini G. Triple inhaled therapy for chronic obstructive pulmonary disease. Drug Discov Today. 2016;21(11):1820-1827.

32. Simeone J, Luthra R, Kaila S, et al. Initiation of triple therapy maintenance treatment among patients with COPD in the US. Inter J Chron Obstruct Pulmon Dis. 2017;12:73-83.

33. Brusselle G, Price D, Gruffydd-Jones K. The inevitable drift to triple therapy in COPD: an analysis of prescribing pathways in the UK. Inter J Chron Obstruct Pulmon Dis. 2015;10:2207-2217.

34. Wurst KE, Punekar YS, Shukla A. Treatment evolution after COPD diagnosis in the UK primary care setting. PLoS One. 2014;9(9): e105296.

35. Albertson T, Murin S, Harper R, Sandrock C. Patient considerations in the treatment of COPD: focus on the new combination inhaler umeclidinium/vilanterol. Patient Prefer Adherence. 2015;9:235-242.

36. Ágh T, Inotai A, Mészáros Á. Factors associated with medication adherence in patients with chronic obstructive pulmonary disease. Respiration. 2011;82(4):328-334.

37. Bryant J, McDonald VM, Boyes A, Sanson-Fisher R, Paul C, Melville J. Improving medication adherence in chronic obstructive pulmonary disease: a systematic review. Respir Res. 2013;14(1):109.

38. Lareau SC, Yawn BP. Improving adherence with inhaler therapy in COPD. Int J Chron Obstruct Pulmon Dis. 2010;5:401-406. 
39. Sanduzzi A, Balbo P, Candoli P, et al. COPD: adherence to therapy. Multidiscip Respir Med. 2014;9(1):60.

40. Dhamane AD, Schwab P, Hopson S, et al. Association between adherence to medications for COPD and medications for other chronic conditions in COPD patients. Int J Chron Obstruct Pulmon Dis. 2017; 12:115-122.

41. Mueller S, Wilke T, Bechtel B, Punekar YS, Mitzner K, Virchow JC. Non-persistence and non-adherence to long-acting COPD medication therapy: a retrospective cohort study based on a large German claims dataset. Respir Med. 2017;122:1-11.

42. Ágh T, Dömötör P, Bártfai Z, Inotai A, Fujsz E, Mészáros Á. Relationship between medication adherence and health-related quality of life in subjects with COPD: a systematic review. Respir Care. 2015;60(2): 297-303.

43. van Boven JF, Chavannes NH, van der Molen T, Rutten-van Mölken MP, Postma MJ, Vegter S. Clinical and economic impact of nonadherence in COPD: a systematic review. Respir Med. 2014a;108(1): $103-113$.
44. Davis JR, Wu B, Kern DM, et al. Impact of nonadherence to inhaled corticosteroid/LABA therapy on COPD exacerbation rates and healthcare costs in a commercially insured US population. Am Health Drug Benefits. 2017;10(2):92-102.

45. van Boven JFM, van Raaij JJ, van der Galiën R, et al. Impact of multipledose versus single-dose inhaler devices on COPD patients' persistence with long-acting $\beta 2$-agonists: a dispensing database analysis. NPJ Prim Care Resp Med. 2014b;24(1):14069.

46. Choudhry NK, Shrank WH, Levin RL, et al. Measuring concurrent adherence to multiple related medications. Am J Manag Care. 2009; 15(7):457-464.

47. Berg KM, Arnsten JH. Practical and conceptual challenges in measuring antiretroviral adherence. J Acquir Immune Defic Syndr. 2006; 43(Suppl 1):S79-S87.

48. Bogart M, Laliberté F, Duh MS, Wu JW, Germain G, Stanford RH. Medication adherence and persistence in chronic obstructive pulmonary disease (COPD) patients on triple therapy in a US commercially insured population. Am J Respir Crit Care Med. 2018;197:A2502.

\section{Publish your work in this journal}

The International Journal of COPD is an international, peer-reviewed journal of therapeutics and pharmacology focusing on concise rapid reporting of clinical studies and reviews in COPD. Special focus is given to the pathophysiological processes underlying the disease, intervention programs, patient focused education, and self management protocols.

\section{Dovepress}

This journal is indexed on PubMed Central, MedLine and CAS. The manuscript management system is completely online and includes a very quick and fair peer-review system, which is all easy to use. Visit $\mathrm{http} / / / \mathrm{www}$.dovepress.com/testimonials.php to read real quotes from published authors. 